\title{
AC 2011-2315: TRANSFER FROM CAPSTONE DESIGN: A MODEL TO FACILITATE STUDENT REFLECTION
}

\section{Susannah Howe, Smith College}

Susannah Howe is the Design Clinic Director in the Picker Engineering Program at Smith College, where she coordinates and teaches the capstone engineering design course. Her current research focuses on innovations in engineering design education, particularly at the capstone level. She is also involved with efforts to foster design learning in middle school students and to support entrepreneurship at primarily undergraduate institutions. Her background is in civil engineering with a focus on structural materials; she holds a B.S.E. degree from Princeton, and M.Eng. and Ph.D. degrees from Cornell.

\section{Mary A. Moriarty, Smith College}

Mary A. Moriarty is an Assessment Researcher with the Picker Engineering Program at Smith College and serves as a private evaluation consultant. She has over 15 years of research, evaluation, and project management experience. Her evaluation work has spanned the areas of science and engineering instruction, robotics, technology application, and disability in higher education. Her background includes serving as Principal Investigator and Project Director for several D.O.E. and NSF initiatives that focused on teaching and learning in higher education. She has a doctorate in Educational Policy, Research, and Administration from the University of Massachusetts, Amherst.

Apurva Errabelli 


\title{
Transfer from Capstone Design: A Model to Facilitate Student Reflection
}

\begin{abstract}
This paper reports on a pilot study designed to gather information about the transfer abilities of capstone students. Students engaged in a set of activities intended to promote student reflection about and documentation of the skills and knowledge they perceive that they will transfer out of their capstone experience. The paper describes the transfer activities (an initial individual written assignment and a team transfer map), and discusses their intent, implementation, and possible variations. These activities were piloted with engineering students near the end of their two-semester capstone design course. As a follow-up, six students, each representing a different project team, were interviewed about their experiences in the transfer activities and their thoughts about transfer in general. The authors independently analyzed the transfer map, written assignments, and interview transcriptions to identify patterns and themes related to transfer.

Results from the activity deliverables and interviews suggest that the transfer activities provide an effective student experience to promote reflection about transfer, document a list of students' main perceived takeaways from their capstone experiences, and, as such, offer data to capstone faculty to improve capstone education. Next steps include implementing a modified version of the activities with capstone alumnae to identify what alumni actually transfer in to their employment after graduation, and investigating whether and how to use these activities as an assessment tool for capstone courses and overall programs.
\end{abstract}

\section{Introduction}

Undergraduate engineering programs commonly culminate in a capstone design course. These one- or two-semester courses meet the ABET requirement of a major design experience ${ }^{1}$ and are intended as an opportunity for students to synthesize their previous learning and apply their knowledge/skills to a complex design problem. Typically these capstone projects involve teams of three to six students who work collaboratively, thus emulating the current engineering workplace environment. ${ }^{2}$ A majority of capstone programs collaborate with industry or governmental organizations so that students tackle real-world design projects for actual clients. ${ }^{2}$ As such, capstone design courses provide a professional practice experience for students, ${ }^{3}$ enabling students a structured opportunity to build and implement their technical and professional skills.

Capstone design courses offer a vast landscape for assessment of student achievement. What capstone instructors choose to assess, however, varies widely, but most often focuses on design outcomes and communication, through the deliverables of team reports and presentations. ${ }^{4}$ Recent initiatives have developed assessment instruments, methodologies, and supporting materials to assist capstone faculty in assessing a range of technical and professional skills, including teamwork and professional development. ${ }^{5,6,7}$ These instruments and methodologies have created an effective set of tools for assessing student achievement along multiple axes. As part of this work engineering programs have begun to encourage students to engage in reflective practices that will facilitate the process of identifying transferable skills. ${ }^{8,9,10}$ Capstone courses approximate professional practice thus serving as a natural transition between students' undergraduate experience and their work and lives after college. In an ideal world, students 
would have a wide range of knowledge and skills from their capstone experience that they could transfer to their future careers. Yet, little is known about what students actually transfer to life after graduation.

\section{Motivation}

The transfer literature is filled with varying definitions and frameworks about what constitutes transfer. While it is not the intent of the authors to advocate for a particular framework, it is important to articulate the theoretical background from which our work originates. Our view of transfer is influenced by the work of Schwartz et al. ${ }^{11}$ In their view, transfer is not necessarily the ability to directly apply what one has learned to new situations but rather an identification of skills and knowledge that best position preparation for future learning. One's ability to directly replicate a set of tasks is therefore not necessarily effective transfer. One's ability to meet future challenges through applying content-independent strategies and interpretations to new challenges is what will ultimately prepare individuals to meet the demands of industry. While understanding the implications of "transfer in" to industry is critical, it is not the focus of this research, though future studies may address this issue. As a first step, there is a need to identify the set of skills that students will take with them when they leave undergraduate education.

Identifying transferable skills is complicated by the broad range of opinions about what skills and knowledge are needed for engineers in the $21^{\text {st }}$ century. Traditional undergraduate engineering education emphasized the acquisition of technical knowledge while more current research includes the importance of the ability to integrate and synthesize knowledge, and skills such as persistence, creativity, innovation, leadership, and teamwork. ${ }^{3,12,13}$ A study conducted by Spinks et al. ${ }^{12}$ indicates that commercial complexity and a broadening global business perspective has driven employer expectations about what is important. Technical skills appeared to be a core requirement for new engineers but were accompanied by the ability to bring theory to practice and by personal skills and attributes such as communication, drive, and enthusiasm. Business and commercial skills such as project management and consumer awareness were also considered critical. A number of studies ${ }^{14,15,16}$ have outlined the importance of specific skills and knowledge for students entering industry. The skills identified in these studies represent a broad range of technical and professional skills that beginning engineers are expected to be able to transfer from their engineering education.

A review of the literature related to transfer indicates there is a significant gap in information related to what knowledge and skills transfer from capstone design courses. Much of the research on skill transfer has focused on the transfer of specific skills gained in training initiatives. These studies predominantly focused on the extent to which knowledge and skills learned in a training setting were transferred to the work environment. ${ }^{17,18} \mathrm{~A}$ few studies have

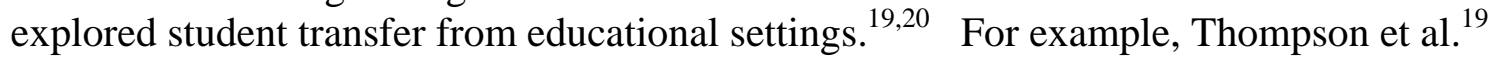
examined the perceived transfer of learning from a distance education Human Resource Development (HRD) program and identified ways in which adult learning principles, HRD strategies, research and evaluation skills, and HRD concepts learned in the classroom were being applied in the work setting. These studies provide valuable insight into general concepts related to skill transfer. However, they are not particularly applicable to the capstone experience that immerses students in real-world applications. 
Identification of transferable skills from capstone design courses is important from a number of perspectives. Business and industry has clearly articulated the need for engineering graduates who come to the workforce ready to step into a challenging and increasingly global work environment; a number of reports have highlighted the need for engineers who are able to deal with complex interrelationships that include not only traditional engineering problems but also encompass human and environmental factors as major components. ${ }^{13,21}$ The capstone design course is intended to help students develop many of the skills identified in these reports. If capstone instructors are to be successful in these endeavors we need to leverage the feedback to improve capstone design instruction. Lastly, identifying transferable skills is important for students in marketing themselves to perspective employers or graduate schools, in identifying potential strengths and weaknesses, and in developing plans for the continued acquisition of important skills. The extent to which students can articulate transferable skills/knowledge and whether or not students appreciate how and why these skills and knowledge will transfer is not currently known.

The purpose of this pilot study was to begin to close the knowledge gap in the capstone transfer literature though preliminary identification of students perceived knowledge of transfer. The intent was to develop and evaluate the effectiveness of a transfer model for enabling student and team reflection, particularly at the end of a capstone design experience. The goal was not to delineate a comprehensive set of perceived skills and knowledge, though that could be done with this model in future work. The model incorporates a set of transfer activities and analysis methods that are described in the following sections. The research for this study was guided by the following questions:

1) Is the overall model an effective method for facilitating reflection about transfer?

2) Are the activities (individual written assignment and team transfer map) effective for identifying transferable skills?

3) How can we use the feedback from the assignments and transfer maps to guide the improvement of capstone education?

\section{Implementation and Deliverables}

The authors developed and pilot tested a pair of activities intended to promote student reflection about and documentation of the skills and knowledge that students will transfer out of their capstone experience. The following sections describe the activities and their origins, the context for the pilot study, and the implementation process and deliverables.

\section{Transfer Activities}

The first component of the pilot study activities is an individual written assignment to encourage individual reflection and accountability. The assignment opens with a warm-up set of prompts for the student to review his/her individual and team learning - including knowledge, skills, and insights - from the capstone design course. The assignment then asks the student to describe his/her intended career plans in the short-term (next three years) and longer-term (10+ years). Combining the warm-up and the career plans, the assignment then instructs the student to 
identify the top five technical lessons and top five project lessons that the student will transfer into his/her career plans.

The second component is a hands-on team-based activity that builds on the individual written assignment. This activity starts by having team members briefly share their individual lists of lessons learned as documented in their individual assignment. For the main activity, teams pool their individual materials and physically create a "transfer map" of their collective transferable knowledge/skills. In this context, the term "transfer map" refers to a version of a "concept map" in which the concepts represent transferable knowledge/skills. Concept maps are visual mechanisms that illustrate the organization of concepts and the connections between them. ${ }^{22}$ They are a useful tool to support learning and assessment, and have been used effectively in engineering education to represent domains of knowledge and increase student understanding of the structure and relationships between various topics. ${ }^{23,24}$ The "transfer map" twist provides the opportunity for teams to identify, synthesize, represent, and organize the team's transferable learning.

Both the individual written assignment and the team transfer map activity were formally documented as part of a module for the Integrated Design Engineering Assessment and Learning System (IDEALS). More information about IDEALS and its current NSF-funded initiative to develop assessments and instructional materials that support student and team growth in designbased courses can be found at http://ideals.tidee.org and through recent publications. ${ }^{6,25,26}$ Both assignments can be downloaded after creating an account on the IDEALS website (https://secure.tidee.org). The Instructor's Guide within the Transferring Knowledge module describes the learning objectives and assignment structure; the transfer activities follow Path B.

\section{Pilot Study Context}

The pilot study was conducted in the capstone engineering design course at Smith College. The Picker Engineering Program at Smith College is one of few engineering programs at a liberal arts college and the only accredited engineering program at a women's institution. The program offers both a B.S. degree in Engineering Science and a B.A. degree in Engineering Arts. As seniors, B.S. students are required to take the two-semester capstone design course, in which they collaborate in teams of 3-4 on projects sponsored by industry and government. In the semester of the pilot study, the capstone course enrolled 22 students divided into 6 project teams.

\section{Implementation Process and Deliverables}

The transfer activities were implemented within the last three weeks of the capstone design course. The individual written assignment was assigned to the class one week before the scheduled class session entitled "Reflection and Transferability". Students were not told what would happen during the class session", which was also the last formal class meeting before the final year-end design project presentations, just that they should complete their individual assignment before the class and bring it with them to class. The course instructor opened the class by recognizing it as the closing class of the year, and by identifying the goals for the class: reflect on learning from the overall capstone experience and discuss transferable lessons from the project/class to next phase of life. Students were asked to sit with their design teams and were given 10 minutes to review their individual written assignments. The course instructor then set up the transfer map activity, with a brief explanation of concept maps, accompanied by a 
handout showing a concept map about concept maps (taken from Novak and Cañas, ${ }^{22}$ p. 2). The instructor stated that the goal of the remainder of the class was for each team to create a "transfer map" representing the team's transferable learning, but did not give any more specific instructions so as not to restrict team creativity. It is worth noting that none of the students had previous experience constructing a concept map, nor did they know previously what a transfer map was. Teams were provided with a wide range of art materials - including large posterboard (one per team), construction paper, markers, stickers, popsicle sticks, pipe cleaners, ribbon, tape, glue, scissors, and a Polaroid camera - plus the remaining 45 minutes of the class to create their maps. At the conclusion of the class, all students submitted their individual written assignments and each team submitted one transfer map. It is important to note that the transfer map was not intended to be an end product; rather, it was a vehicle to facilitate team discussion about learning and synthesis.

\section{Analysis Methodology}

As previously indicated the intent of the study was to develop and evaluate the effectiveness of a transfer model for enabling student and team reflection, particularly at the end of a capstone design experience. The purpose of the study was threefold: (1) to determine if a transfer reflection activity and map and associated analyses are a useful ways to facilitate reflection about learning/transfer, (2) to identify perceived knowledge and skills transferred from a capstone course, and (3) to determine how feedback about transfer can be used to improve capstone education. The study used a qualitative research design to explore the impact of transfer activities on students in the capstone course. Consistent with the qualitative methods, research participants were chosen using purposeful sampling. Johnson and Christianson ${ }^{27}$ define purposeful or purpose sampling as the process used when cases are selected because they provide in-depth information needed to address the research questions. The 22 students (six teams) created six transfer maps. All students were invited to participant in follow-up interviews; six students (one from each team) were randomly selected from the group who volunteered. Interviewees were given a small monetary gift certificate as an incentive to participate.

Data available for analysis included the individual written transfer assignments from the six participants, the six team-based transfer maps, and the interview transcripts. The intent of the written assignment was to encourage the process of thinking about transfer in order to prepare students to create the map and to document individual thoughts about transfer. Thus, these assignments were not analyzed individually. Rather, the content was used as a cross-reference for the team transfer maps. The six team transfer maps were reviewed for general content and themes. Since the research questions are aligned with the more subtle concepts that relate to process and effectiveness, the participant interviews became the primary source of analysis. The interviews provided an in-depth exploration of the meaning and process of map creation, while the data from the assignment and maps served as a method to validate and triangulate data.

The six student participants were interviewed for 20-30 minutes using a semi-structured protocol that consisted of questions that were geared to elicit responses about the process, content, and usefulness of the transfer activities. To ensure validity and minimize bias, interviews were conducted by one of the researchers not involved in the capstone instruction but trained in qualitative methodology. Interviews were video-taped, transcribed, and independently analyzed 
by the three authors. Data from the interviews were coded and sorted into categories and subcategories. Anfara, Brown, and Mangione ${ }^{28}$ recommend the use of tabular strategies for documenting the relationship between data sources and categories in order to strengthen credibility and provide a visual representation of methodological rigor. Adapted from the work of Constas ${ }^{29}$ and Brown ${ }^{30}$, the model shows three levels of analysis. Level 1 depicts open coding. Level 2 depicts the consolidation of those units into more manageable and workable units. Level 3 is the final iteration of category development. In Level 2, central categories were identified. This process of categorization created 13 overall categories; though they are not all a focus of this study. It is notable that the knowledge and skills identified in Level 2 coding fit within the central categories of technical, interpersonal, and professional identified by Davis et al. in their proposed engineer profile. ${ }^{31}$ The six categories that best addressed the guiding research questions were selected for further coding. From those six, four main themes (Growth, Impact, Learning Process, and Map Process) were selected for full discussion based on a review of the individual assignments and transfer maps, on final coding, and applicability to the research questions. Figure 1 shows the final two levels of categorization and the selected four main themes.

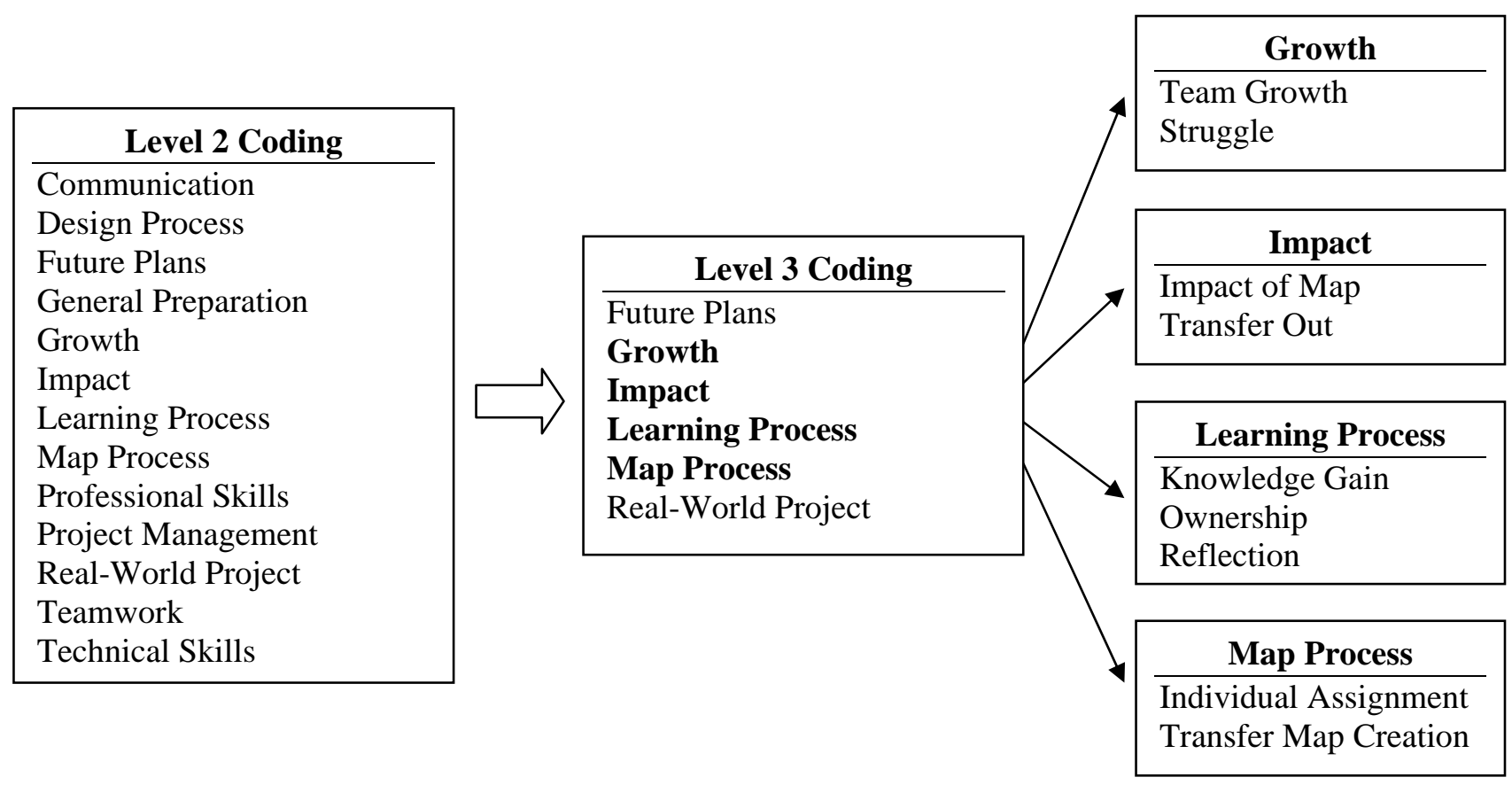

Figure 1. Categorization and Theme Selection

\section{Results and Discussion}

The pilot study led to many interesting findings regarding student transfer from the capstone course. This section presents results and discussion of the individual written assignment and the team transfer maps, in turn, followed by in-depth discussion of the three selected themes in the interviews. Drawing on this information, the section addresses the significance of this work by answering the guiding questions that motivated this pilot study. 


\section{Individual Written Assignment}

The individual written assignments all followed a similar form, guided by the structure of the assignment: brief discussion of short and longer term career plans, a list with short explanation of five technical lessons to transfer, and a list with short explanation of five project lessons to transfer. Both sets of lists spanned a breadth of topics, including topical content such as "hydraulics" and "machining" and "project management", as well as more subtle concepts such as "accepting what you know and don't know" and "revisit assumptions". While many students differentiated between technical and project skills, some students also included items that seemed like professional skills, such as "negotiation", on their technical lists. Most students provided compelling explanations to support the items on their lists, making the connections between the items and their future plans. Figure 2 shows one student's list of the technical and project lessons that she perceives will transfer, plus her supporting explanation for one item on each list.

\begin{tabular}{|l|l|}
\hline \multicolumn{1}{|c|}{ Top 5 Technical Lessons } & $\begin{array}{l}\text { "It wasn't until someone during one of our design } \\
\text { reviews asked a question about how we are validating } \\
\text { Importance of validating models }\end{array}$ \\
$\begin{array}{l}\text { Use of MATLAB } \\
\text { Concept selection } \\
\text { Splitting up work on a complex code } \\
\text { Prototype building }\end{array} \quad \begin{array}{l}\text { why we would do that and how we could achieve it. } \\
\text { Understanding the importance of validating computer } \\
\text { models will play an important role in my work as } \\
\text { analyst for [consulting company] since I will be doing } \\
\text { a lot of analyzing and simulation, and it will be } \\
\text { helpful to have a clear idea of how I can validate my } \\
\text { data before pitching to clients." }\end{array}$ \\
\hline
\end{tabular}

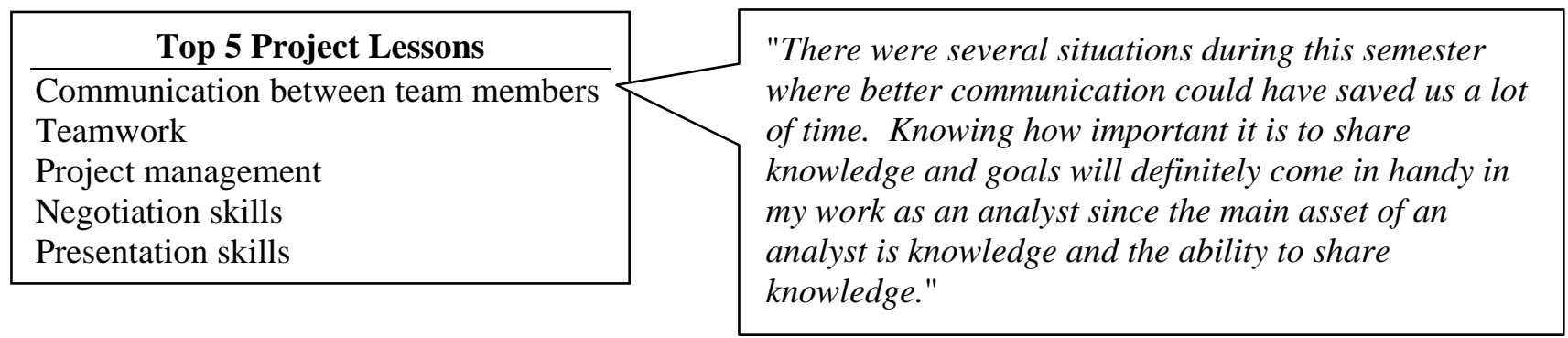

Figure 2. Excerpt of Written Assignment for Student 2: Lists of Top 5 Technical and Project Lessons to Transfer plus Sample Supporting Explanations

Team Transfer Maps

As previously indicated the team transfer maps were created using a wide range of art materials. Therefore, student teams were able to personalize their maps through artistic representation, shapes, colors, and layout. Each of the transfer maps looks very different with varying levels of detail and complexity. Shapes, color, and 3D layouts were used to differentiate between concepts, organize, and represent input and output. The maps are not intended to reflect depth of knowledge but rather those skills that students perceive they will transfer. As an example, 
Figure 3 is a photograph of the map created by Team 1 . The four members of the team worked on a whiteboard first to collect ideas, then transferred their ideas to the transfer map. The map shows the hierarchy of concepts, the progression and flow of transferable skills, and the mapping of skills and knowledge to the future. The project specific themes and technical content are depicted in the soup of ideas in the background, while the key learning is depicted in the clouds that rise above. All of these factors lead to technical and professional skills shown in a briefcase for the future. As indicated in Figure 3, the map clearly demonstrates the specific skills and shows a natural progression or flow to the future. However, there is no distinction between the types of skills and there is no representation of how the skills are linked together.

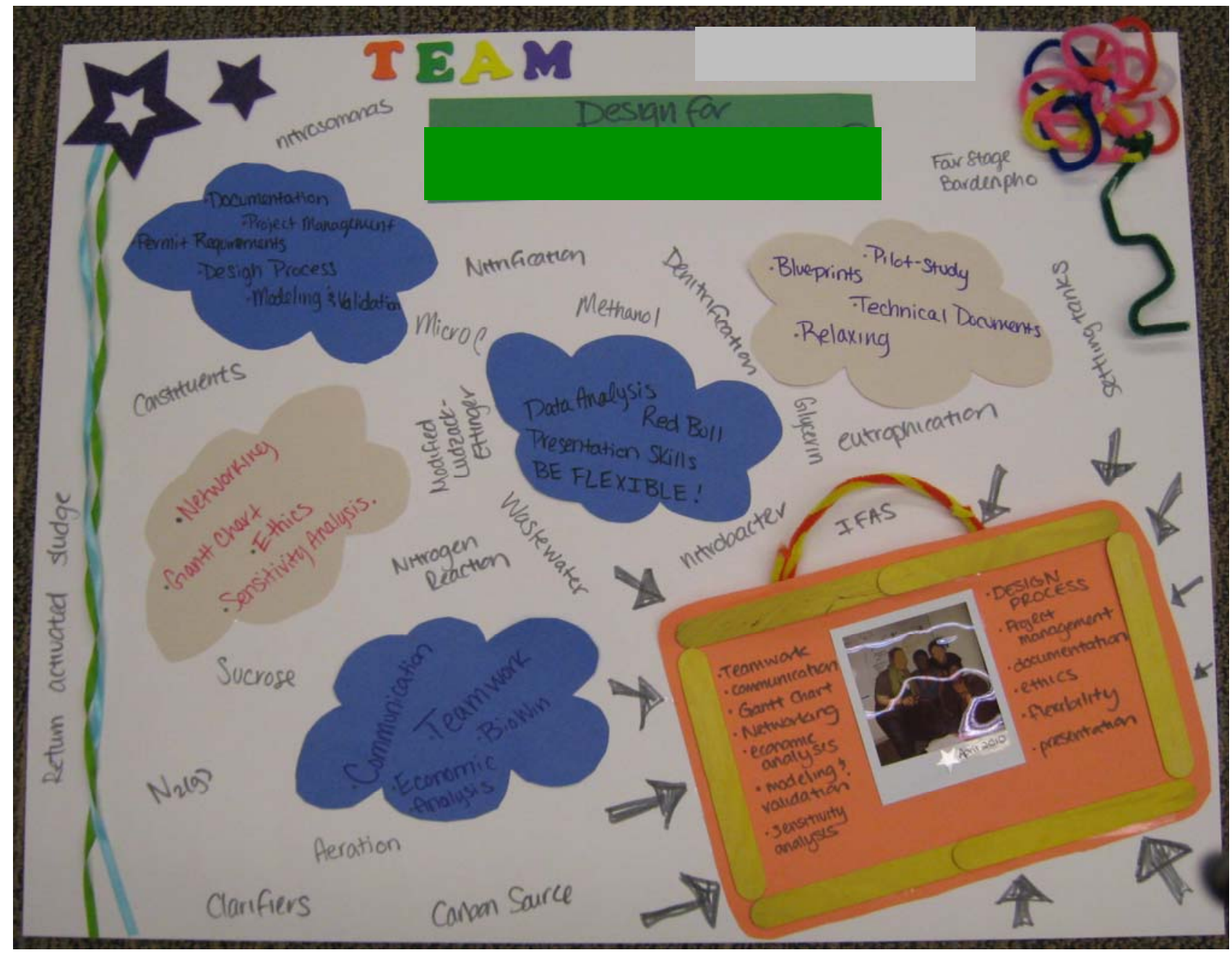

Figure 3. Photo of Transfer Map for Team 1

(Identifying team information has been removed for confidentiality purposes.)

While the layout and design of the other maps were different from that depicted in Figure 3, there were some consistent themes. For example, all of the maps, with the exception of that created by Team 6 , showed organizational categories that included both technical and 
professional skills. These five maps all identified some variation of technical skills, project management skills, design process, communication, and team related skills. Four of the six maps specifically noted project-specific technical skills, while three noted a direct flow to the future. One additional map referred to the future by labeling their overall map "Guide to the Future" but did not specifically show how skills flowed outward or linked to the future. Even though the linking of concepts is a distinguishing characteristic of concept maps it was not clearly evident in most of the team transfer maps, perhaps because the focus on transfer suggested flow more than connections. Only two of the maps showed direct links between specific skills and overarching themes, though the layouts of two other maps suggested that skills were aligned with these themes.

In contrast to the five maps mentioned above, Team 6 created a very different kind of map. This map lacked identification of skills and seemed to be more of a representation of the team's overall experience. The items appeared to represent struggle, faces drawn on stick figures were serious, and the word "work" was depicted dangling over flames. Interestingly enough the final arrow led to a star accompanied by the word "done", seeming to indicate that the process of completion may have been the overriding accomplishment for this team.

With the exception of Team 6, team maps were clear representation of the skills and knowledge that students perceived they would transfer out to the future. At the same time, the authors recognize that visual representations are subject to interpretation and may not provide in-depth information. Moreover, the tangible maps themselves were not the objective but rather a vehicle to better facilitate team discussion of transferable skills. As a result, the remaining maps are not shown, in part for confidentiality, and in part to focus instead on a more in-depth analysis. In order to gain this deeper perceptive and to understand the process and meaning individual interviews were conducted with one representative from each team.

\section{Interviews}

The interviews provided rich discussion that supported and extended the information contained in the individual written assignments and the team transfer maps. Whereas the written assignments and transfer maps simply stated/depicted selected transferable skills/knowledge, the interviews revealed insights and in-depth explanation of individual decisions, team process, learning approaches, and student growth. Each interview was associated with one of the six team transfer maps, thus enriching the researchers' initial interpretation of the transfer maps. The four main themes (Map Process, Learning Process, Growth, and Impact) selected from the transcript analysis are discussed below.

Map Process: Prompted by the interview questions, all six interviewees discussed process with regard to the transfer maps, their process of creating the team transfer map, and the role of the individual assignment in the map creation. As a starting point, all students were able to articulate the process they used to make the map. Some teams followed an intentional logical process, and others were less structured:

We started by separating the technical skills versus the process related skills. (S4) 
We actually made a list on paper to write down what goes in each category... We split up our map into different areas of transferability. (S2)

We decided to just get a bunch of colors and shapes and kind of throw them in the middle. (S6)

Interestingly, several of the students commented that their process of making the map was a reflection of their overall team process throughout the project:

We each shouted different things at each other and said ok so what do we want to see, and then we just kind of went for it.... that represented how we went through the project too. (S1)

It just sort of organically came together in a sort of crazy way, which is exactly how all of our prototypes came together, so it sort of made sense. Um, yeah, different people doing different things. (S3)

The lack of time to fully complete the map was a common refrain: "I wish we had more time, ... by the time it was over was really the time we were kind of trying to understand what we wanted to get across." (S6) Additionally, one student noted but appreciated the lack of structure in the assignment: "I didn't really think we had a whole lotta guidance on this. But that's what I like about it. I feel like if there were any more guidelines on this it would make them all cookiecutter." (S6)

Students felt very strongly that the individual written assignment served as a useful precursor to the team transfer map, facilitating an initial individual reflection and providing a foundation for the team to build on:

It was definitely important to have the individual assignment beforehand because it helped us get each individual's ideas down. (S2)

I think the individual assignment was a really good assignment to get the juices flowing. Even not writing all those things down, but reading those questions and kind of thinking about them really started moving me in a good direction to be able to create this. So I thought they were very nice, coupling wise. (S5)

One student appreciated the individual assignment because she could represent her own thoughts without having to compromise with her teammates, whereas another student appreciated seeing her teammates' individual assignments because they included items she herself had forgotten on her own list. While several of the students admitted to not taking the assignment too seriously or felt it bordered on busy work, other students valued the (required) opportunity to reflect on their own learning: "writing about each process and each skill that I learned helped me see how prepared I am for this next step [after graduation]. So it was a good way to reflect on my own self. On my personal knowledge ... what I've learned." (S4) One student felt very strongly that the assignment should not mandate a list of five technical or project lessons: "I just hate that 
kind of restraint. ... What if only two things really mattered to you? I feel like I would have done a better job describing the ones that really meant something to me." (S6)

Learning Process: As they had documented in their team transfer maps, the interviewees also articulated skills and knowledge that they believed they acquired during their capstone experience. Skills like project management, design, communication, teamwork, and specific technical processes were mentioned by a number of students. However, in the interviews the importance of learning the more subtle concepts became much more evident. For example, students reported having acquired knowledge in areas such as "how to be a good worker, work balance, and efficiency" (S6). One student reported that she learned the importance of being aware of the time spent on tasks:

Being aware of logging my tasks, I feel like you have to, have to know how long a task is going to take because if you don't you know you could go over budget, you could miss some deadlines. (S6)

Other students framed the concept in a similar manner:

Organizing all of our information, that's one thing that I learned a lot. But even though you can say to your teammates, all right everyone submit on Sunday night at 9 PM, it doesn't always happen. (S1)

I had a terrible time trying to write the progress reports every week. It was like I just didn't know how to get all of the information in a way that makes sense. And, so kind of seeing how we evolved through that and at the end, we were kind of having good ones that you know, had all the information and everything like that. (S3)

All of these students identified subtle concepts that might fall within the category of project management or organization but were not necessarily evident on the team transfer maps.

In addition to being able to articulate the ways in which the transfer activities helped them to identify specific skills, some students talked about how the process of reflection was an integral part of learning. Early reflection can result in actually developing skills that are needed for the future as indicated by the following comment:

We kind of knew...that we wanted to learn programming MATLAB, so we actually designed our project around being able to learn MATLAB. So there were some skills that we knew beforehand...we created our project around creating that transferable skill. (S2)

This taking responsibility or ownership for one's own learning is a theme that surfaced in a number of interviews. Several students indicated ownership of their learning in the following ways:

I think I got something that I didn't expect...learning how to learn. Learning 
how to teach myself how to rapid prototype and make a drawing for the machine shop and you know learning...not about specific technical things.... It's not about the project, it's about the process. (S3)

We could go from liking the project to not liking it, because we didn't feel connected to it, and we'd have to go back and think; well I'm supposed to learn something out of it. What am I going to learn? What do I expect to learn? And then we'd go back to the list [of things important to the team] and say, okay I'll work on my communication and do that, or work on documentation. That was a big thing for us. (S1)

In addition to developing this sense of ownership about their learning several of the students seemed to recognize that the learning process in the capstone course was different than in their other courses. There seemed to be recognition of how the real-world application differed from other academic courses and how this impacted their learning:

I think the biggest difference here was that there wasn't somebody around that laid out every single step for us... and then also in a class project you usually get regular assignment sheets that kind of lead you through a project in baby-steps, whereas in this project we just got the project and we're told, go. (S2)

We didn't get one thing and then learn something else, and then learn something else, it kind of all happened at once, well, it kind of, we, you know we had more than one thing you were working on at one time, and when you were half way through one thing something else would come. (S6)

Balance, organization, responsibility and ownership rose out of the interview process. These learning themes were not quite as evident in either the individual assignments or the team transfer maps. Yet, they represent critical concepts that contribute to the overall growth and development of students as they transition to life after graduation.

Growth: Building on their discussion of the learning process, students in the interviews also openly discussed the concept of growth, both in terms of growth across the team and growth through struggle. Some students discussed how they recognized and documented growth through making their team transfer maps:

And making this poster [transfer map] we got to see where our teammates grew and what's more important for them, what they learned. (S4)

I guess one way we could have done the poster is had individuals put what their biggest takeaways, but I think, especially in our group, we struggled so hard together that we wanted to put up the hardest things for us a team. (S6)

Other students noted that the transfer maps reflected the struggle and growth that the teams had experienced during the project: 
I think that different people learned a lot of things about conflict and solution [motions to transfer map]. We had some problems with conflict, and learning about how to manage people was a big thing that a lot of us struggled with. (S3)

This project has forced us to grow in all of these things [listed on the map]. It made us get to this specific level, and so that level is going to be transferrable everywhere, in the same degree. But getting to that level based on our different backgrounds needed growth more in certain areas than others. (S5)

One student, who was overcome with emotion at one point in the interview, summarized her insights about struggle, growth, and transfer very succinctly: "The things we really struggled with the most are what we're going to take with us." (S6)

Impact: The information gathered from maps and interviews has provided rich data about transfer skills, student learning process, and growth but what of the actual impact of the activities on students? On the simplest level the majority of students interviewed reported that the individual assignments were useful for facilitating individual reflection and that their teams enjoyed the experience of creating transfer maps, that "getting out of the strict margins, and just working with this [the transfer map] and reflecting" (S4) was fun.

For some students the combined activities increased their awareness of their own transferable skills. One student suggested that working together with her teammates on the team transfer maps allowed for a more comprehensive understanding of her skill transfer:

It was really the situation where everybody was like, oh yeah, I should have done that, I forgot about that... and it was like bringing together 4 people's views... I don't think that there's a single item on that list that not everybody thought was an important part of transferability. (S2)

I would never have thought about putting down double checking calculations... it is somehow so natural that I don't think of it as a transferable skill... it's a really interesting focus on detail that came out and just brought up, oh my god, so many other skills that are transferable that I hadn't thought about because I was just thinking about the big picture. (S2)

Interestingly, other students saw value in the process of synthesizing the details into the big picture. One student talked about the combined impact of talking about their individual assignments and creating the team transfer map:

Talking about it was directly applicable to creating this [team transfer map], and making it, um, kind of connected to everyone and, um, just get the big picture... I like big picture, and connections, and things that go in a circle... this was so powerful for me. (S5)

These differences of the impact on the teams can be noted in other areas as well. For some teams the transfer map activity served as closure: "it was a way for us to be connected together as a team" (S1); for other students it was a way to review what they learned through the year: "it's a 
recap of everything I learned" (S4). Some students also noted that the maps and the process of creating them reflected the team itself:

I feel the most significant part of this is the actual process of making this [team transfer map] because we worked together, this poster here represents, really represents who we are. (S4)

For another team, the transfer map activity served as a way to process some of the struggles they had through the semester:

Parts of our project created angst, like they created unhappy feelings. But I feel like when we put them on the map they weren't unhappy... it was kind of like we were all acknowledging like how hard we worked together as a team. (S6)

Overall, the transfer activities seemed to have a positive impact on the participants, while at the same time serving slightly different purposes for different teams depending on individual needs. All the interviewees indicted that transfer and thinking about transfer was important. They also noted that they benefited from the time spent reflecting on transfer. One student summed up the experience by stating:

I was really worried about, like okay, I have a college education, but what do I actually take out of my college experience and how do I transfer it to a job...Especially this assignment [team transfer map] made it clear how much there actually is to transfer out. But, without the assignment I feel like I wouldn't have really realized it. (S2)

\section{Significance}

This section returns to three primary questions motivating this pilot study as a means to synthesize the extensive data from the individual assignments, team transfer maps, and follow-up interviews discussed above.

Q1: Does the model effectively facilitate reflection about transfer?

The review of all three data sets (individual written assignments, team transfer maps, and interviews) showed that the model is an effective method for facilitating reflection about transfer. The written assignment served to focus students on their individual experience, while the team conversations and transfer map allowed for a more comprehensive examination of transferable skills by team members. An analysis of the individual interview transcripts confirmed that the activities were useful and that the process (at least for this group of students) did result in students thinking more deeply about what skills they would be transferring out to graduate school or work. However, it should be noted that only a small sample of students were interviewed and interviewees were selected from a group of students who volunteered. Therefore, it is difficult to generalize to all students in the class.

Nevertheless, an informal observation of the class in which the maps were created showed that the class was alive with activity. Students were very engaged with each other and seemed to be 
genuinely interested in the topic. Maps were created in the last class of the semester at a time when there were significant project demands, making it particularly noteworthy for students to be so engaged in this type of activity.

In addition to serving as a means of reflection, the team transfer map activity had other surprising consequences. For some teams the activity served as a culminating activity, as a way to end an intensive year of work together, while for other teams the activity seemed to bring about a needed closure to a difficult year. The overall activities worked well for this group of students. It should be noted, however, that these students are accustomed to a curriculum that utilizes out-of-the-box activities and that throughout their undergraduate education they have been asked to reflect on their experiences. The transfer activities may not work as well for different types of groups or may need modification depending on the nature of the institution. For example, using electronic media to create maps as opposed to art materials might be more appealing for some students. Pilot testing of the model in different settings and with different capstone populations would demonstrate whether the activities are equally effective with a range of students and institutional cultures.

Q2: Are the activities effective for identifying transferable skills?

The individual written assignment served to create lists of transferable skills in both the technical and professional areas. The items on the list could easily be quantified to capture the frequency of specific skills, thereby creating a method for an instructor or program to identifying perceived transfer skills. However, the validity might be questionable given that some students admitted to not taking the written assignment seriously and others may have provided a list of what they thought the professor wanted. Moreover, it is worth noting that the origin of specific knowledge or skills (perceived to transfer) may not be attributed to the capstone experience alone and cannot be determined without doing a baseline activity at the beginning of the course. Such an activity could be considered for future studies.

The discussion did bring in richer detail and a greater awareness of transferable skills that might have been missed in the written assignment. The team transfer map activity then provided a structure to organize and visually represent transfer knowledge and skills. The process itself engaged students on multiple levels, utilizing auditory, visual, and tactile senses. The method is consistent with current literature in the field that points to the need for using multimodal learning methods to reach diverse learners ${ }^{32}$ and to the need to engage students in the learning process ${ }^{33}$. The process also helped students to synthesize and distill information so that important transferable skills could be identified.

The intent of the individual interview was to gain a better understanding of the process and of the student experience so that the effectiveness could be evaluated. The data confirmed that the overall experience was effective but also revealed much more. The interview data provided information that was not obvious from the activities and thus gave a deeper understanding of the experience and skills. The interview data became integral to truly understanding transferable skills and the associated learning processes and growth. Interviewing, transcribing, and analyzing data represents a considerable investment of time and energy on the part of researchers; at the same time this analysis provided enhanced understanding. Other (perhaps less 
time intensive) methods for obtaining these data such as student audio recordings or structured questions about the process will be explored in future research.

Q3: How can feedback be used to guide capstone education?

This pilot study and the associated data analysis suggest that the transfer activities are a valuable experience for students (at least at this one institution); the students appreciate having designated time to reflect and look forward, as well as to bring closure to their team experience. As such, the authors plan to continue implementing the individual assignment and the team transfer map in subsequent years. Capstone design educators elsewhere may want to consider incorporating transfer activities like this in the final few weeks of their own capstone design courses to promote reflection and transfer discussions.

In addition, the deliverables from the two activities provide information that may inform capstone design courses or pedagogy. First, because the activities capture student perception of transferable skills/knowledge, these data may help capstone instructors in aligning course content/projects with student interest and career paths. Second, the activities provide a snapshot of overall team experiences, highlighting where there have been difficulties and successes in teams; this information may help educators think about how teams and teamwork are structured and scaffolded in subsequent years.

In this study, transfer activities were implemented primarily to provide a student experience and to identify perceived transfer skills. Therefore, the utilization of these activities as a method of assessment or evaluation cannot be directly addressed. Concept maps have been successfully used in course assessment and as a method of evaluating program objectives. ${ }^{24,34}$ Whether similar analysis techniques could be applied to transfer maps or the individual assignment is as yet unknown. Given the potential that such an assessment could greatly enhance current programmatic and ABET accreditation reviews, this topic is worthy of future study.

The next steps for this work are to implement the activities with alumnae, so as to capture what skills/knowledge the alumnae actually transferred, beyond just what the graduating seniors perceived they would transfer in the future. Plans are to recruit alumnae at various points in their career with a range of career paths. The authors intend to work with both individuals and teams, likely facilitating the team transfer map activity through electronic tools. The combination of data from both graduating seniors and alumnae will deepen our understanding of transfer from the capstone course, facilitating continued improvements of the capstone design experience, and the engineering program overall, to better prepare students for a variety of careers after graduation.

\section{Conclusions}

Student recognition of transferable skills and knowledge is particularly important in capstone courses, which are often geared toward preparing students for professional practice. The pilot study discussed in this paper was conducted to develop and evaluate the effectiveness of two transfer activities for facilitating student and team reflection about transfer, particularly at the end of a capstone design experience. Students engaged in two activities (an individual written assignment and a team transfer map) regarding knowledge and skills they perceive that they 
would transfer out of their capstone experience. The activities were implemented in the capstone engineering design course less than three weeks from the end of the course; six students (one from each project team) were interviewed after classes ended to capture their experiences in the transfer activities and to enrich and support the data from the transfer activities themselves. The authors reviewed the individual assignments and transfer maps and also completed an in-depth qualitative analysis of the follow-up interviews. Multiple categories of knowledge and skills emerged from the qualitative analysis; those categories that best addressed the research questions were selected for in-depth analysis. The results of this analysis suggest that these activities are an effective means to facilitate student reflection about transfer, on both an individual and team level, and that they help to bring closure to the capstone experience. Moreover, the activities highlight the knowledge and skills that students perceive they will transfer to their lives after graduation; this information may aid capstone educators in course modifications. Future work includes piloting the activities with alumnae, implementing the activities in different institutional contexts, and investigating whether the activities can be useful as an assessment tool.

\section{Acknowledgements}

The authors would like to acknowledge the students in Smith's capstone design course for participating in both the individual and team transfer activities. The authors are particularly grateful to the six students who shared their candid thoughts and impressions during the followup interviews. The authors also thank the anonymous reviewers for their suggestions to improve the clarity of the paper. This work was inspired through discussions about transfer with the inaugural group of Teaching Fellows supported by the Sherrerd Center for Teaching and Learning at Smith College.

\section{Bibliography}

[1] ABET. (2009). Criteria for Accrediting Engineering Programs, Engineering Accreditation Commission, http://www.abet.org/Linked\%20Documents-UPDATE/Criteria\%20and\%20PP/E001\%2010-

11\%20EAC\%20Criteria\%201-27-10.pdf, accessed January 2011.

[2] Howe, S. (2010). Where Are We Now: Statistics on Capstone Courses Nationwide. Advances in Engineering Education, 2(1). http://advances.asee.org/vol02/issue01/03.cfm, accessed January 2011.

[3] Sheppard, S., Macatangay, K., Colby, A., and Sullivan, W. (2009). Educating Engineers: Designing for the Future of the Field. San Francisco: Jossey-Bass.

[4] McKenzie, L., Trevisan, M., Davis, D., and Beyerlein, S. (2004). Capstone Design Courses and Assessment: A National Study. Proceedings of the American Society for Engineering Education Annual Conference, Salt Lake City, UT.

[5] Layton, R.A., Loughry, M.L., Ohland, M.W. and Pomeranz, H.R. (2007). Software for Student Team Formation And Peer Evaluation: CATME Incorporates Team-Maker, Proceedings of the American Society for Engineering Education Annual Conference, Honolulu, HI.

[6] Davis, D., Trevisan, M., Gerlick, R., Davis, H., McCormack, J., Beyerlein, S., Thompson, P., Howe, S., Leiffer, P., and Brackin, P. (2011). IDEALS: A Model for Integrating Engineering Design Professional Skills Assessment 
and Learning. Proceedings of the American Society for Engineering Education Annual Conference, Vancouver, BC Canada.

[7] McNair, L., Paretti, M., Wolfe, M.L., and Knott, T. (2006). Defining and Assessing the ABET Professional Skills Using E-Portfolio. Proceedings of the American Society for Engineering Education Annual Conference, Chicago, IL.

[8] Gerlick, R., Davis, D., Brown, S., and Trevisan, M. (2010). Reflective Practices of Engineering Capstone Design Teams. Proceedings of the American Society for Engineering Education Annual Conference, Louisville, KY.

[9] Socha, D., Razmov, V., and Davis, E. (2003). Teaching Reflective Skills in an Engineering Course. Proceedings of the American Society for Engineering Education Annual Conference, Nashville, TN.

[10] Siewiorek, N., Shuman, L., Besterfield-Sacre, M., and Santelli, K. (2010). Engineering, Reflection, and Life Long Learning. Proceedings of the American Society for Engineering Education Annual Conference, Louisville, KY.

[11] Schwartz, D. L., Bransford, J. D., and Sears, D. L. (2005). Efficiency and Innovation in Transfer. In J. Mestre (Ed.), Transfer of Learning from a Modern Multidisciplinary Perspective. CT: Information Age Publishing, 1-51.

[12] Spinks, N., Nicholas, L.J., and Birchall, D.W. (2007). Making it All Work: The Engineering Graduate of the Future, a UK Perspective. European Journal of Engineering Education, 32(3), 325-335.

[13] National Academy of Engineering. (2004). The Engineer of 2020: Visions of Engineering in the New Century, Washington, DC: The National Academies Press.

[14] Magee, C. L. (2004). Needs and Possibilities for Engineering Education: One Industrial/Academic Perspective, International Journal of Engineering Education, 20(3), 341-352.

[15] Lang, J., Cruse, S., McVey, F., and McMasters, J. (1999). Industry Expectations of New Engineers: A Survey to Assist Curriculum Designers. Journal of Engineering Education, 88(1), 43-51.

[16] Todd, R.H., Sorrensen, C.D., and Magleby, S.P. (1993). Designing a Capstone Senior Course to Satisfy Industrial Customers, Journal of Engineering Education, 82(2), 92-100.

[17] Ford, J.K. (1997). Transfer of Training: An Updated Review and Analysis. Performance Improvement Quarterly, 10(2), 22-41.

[18] Brinkerhoff, R.O., and Montesino, M.U. (1995). Partnerships for Training Transfer: Lessons from a Corporate Study, Human Resource Development Quarterly, 6(3), 263-274.

[19] Thompson, D.E., Brooks, K., and Lizarraga, S. (2003). Perceived Transfer of Learning: From the Distance Education Classroom to the Workplace, Assessment and Evaluation in Higher Education, 28(5), 539-547.

[20] Schaefle, S., Smaby, M. H., Maddux, C. D., and Cates, J. (2005). Counseling Skills Attainment, Retention, and Transfer as Measured by the Skilled Counseling Scale, Counselor Education and Supervision, 44(4), 280-292.

[21] National Science Board (NSB) 07-122 (2007). Moving Forward to Improve Engineering Education. National Science Foundation, National Science Board.

[22] Novak, J. D. and Cañas, A. J. (2008). The Theory Underlying Concept Maps and How to Construct Them. Technical Report IHMC CmapTools 2006-01 Rev 01-2008, Florida Institute for Human and Machine Cognition, http://cmap.ihmc.us/Publications/ResearchPapers/TheoryUnderlyingConceptMaps.pdf, accessed January 2011.

[23] Ellis, G. W., Rudnitsky, A., and Silverstein, B. (2004). Using Concept Maps to Enhance Understanding in Engineering Education. International Journal of Engineering Education, 20(6) ,1012-1021. 
[24] Gerchak, J., Besterfield-Sacre, M., Shuman, L.J., and Wolfe, H. (2003). Using Concept Maps for Evaluating Program Objectives. Proceedings of the ASEE/IEEE Frontiers in Education Conference, Boulder, CO.

[25] Davis, D., Trevisan, M., Gerlick, R., Davis, H., McCormack, J., Beyerlein, S., Thompson, P., Howe, S., Leiffer, P., and Brackin, P. (2010). Assessing Team Member Citizenship in Capstone Engineering Design Courses.

International Journal of Engineering Education, 26(4), 771-783.

[26] McCormack, J., Beyerlein, S., Feldon, D., Davis, D., Davis, H., Wemlinger, Z., Gerlick, R., and Howe, S. (2009). Methodology for Selection, Sequencing, and Deployment of Activities in a Capstone Design Course Using the TIDEE Web-based Assessment System. Proceedings of the American Society of Mechanical Engineers International Design Engineering Technical Conferences \& Computers and Information in Engineering Conference. San Diego,CA.

[27] Johnson, B., and Christenson, L. (2004). Educational Research: Quantitative, Qualitative, and Mixed Approaches ( $2^{\text {nd }}$ ed.). Boston: Pearson.

[28] Anfara, V.A., Jr., Brown, K.M., and Mangione, T.L. (2002). Qualitative Analysis on Stage: Making the Research Process More Public. Educational Researcher, 31(7), 28-38.

[29] Constas, M.A. (1992). Qualitative Analysis as a Public Event: The Documentation of Category Development Procedures. American Educational Research Journal, 29(2), 253-266.

[30] Brown, K. (1999). Creating Community in Middle Schools: Interdisciplinary Teaming and Advisory Programs. Unpublished doctoral dissertation, Temple University, Philadelphia.

[31] Davis, D.C., Beyerlein, S.T., and Davis, I.T. (2005). Development and Use of an Engineer Profile. Proceedings of the American Society for Engineering Education Annual Conference, Portland, OR.

[32] Burgstahler, S.E., and Cory, R.C. (2008). Universal Design in Higher Education. Cambridge: Harvard Press.

[33] Bransford, J.D., Brown, A.L., and Cocking, R.R. (Eds), (2000). How People Learn: Brain, Mind, Experience, and School, Washington, DC: National Academy Press.

[34] Besterfield-Sacre, M., Gerchak, J., Lyons, M., Shuman, L.J., and Wolfe , H. (2004). Scoring Concept Maps: Development of an Integrated Rubric for Assessing Engineering Education, Journal of Engineering Education, 93(2), 105-116. 